\title{
Correlative Microscopy in the Laboratory: Analysis of the Triple-Phase Boundary in a Solid-Oxide Fuel Cell Electrode Using X-Ray Computed Nanotomography and FIB-SEM
}

\author{
P. R. Shearing, ${ }^{*}$ J. Gelb, ${ }^{* *}$ and N. P. Brandon * \\ * Department of Earth Science and Engineering, Imperial College, London, UK \\ ** Xradia, Inc., Concord, CA 94520
}

Solid Oxide Fuel Cells (SOFC) are high-temperature electrochemical devices with the potential for green and economic power generation. Electrochemistry of SOFCs has been the subject of intensive research for a number of years; however, there remains a limited understanding of the link between the electrochemical performance and the microstructure of SOFC electrodes. In widely used composite electrodes, the final performance is believed to be highly dependent on the intimate contact of ionic, electronic, and pore phases at so-called triple phase boundaries [1]. Recent advances in tomography techniques have enabled detailed 3D studies of SOFC electrode microstructures, from which the pore connectivity, tortuosity, and volume fraction of the ceramic and metallic phases may be extracted.

In order to effectively characterize the microstructure of a Ni-YSZ SOFC electrode in 3D, an experimental approach was developed using a combination of $\mathrm{x}$-ray nanotomography and FIB-SEM. In the first step, a novel FIB lift-out technique produced a sample size suitable for x-ray nanotomography, producing a sample with Greatest Feret Diameter such that the sample was completely contained within the x-ray field of view throughout rotation [3]. Following this, nondestructive $\mathrm{x}$-ray nano-CT was performed using the Xradia nanoXCT laboratory CT scanner utilizing both the highest-resolution and larger field of view modes (50 and $150 \mathrm{~nm}$ resolution, respectively) [4]. In an additional experiment, characterization of a Ni-YSZ sample from the same batch was conducted using a Zeiss NVision FIB-SEM system for a correlation study to the x-ray nano-CT results $[2,5]$.

The results of the two virtualization experiments demonstrated a remarkable correlation for porosity calculations, as shown in Table 1. Whilst there was not enough contrast to reliably segment Ni from YSZ using laboratory $\mathrm{x}$-ray nano-CT, the pore phase volume occupation showed very similar results to those obtained using FIB-SEM [2]. These results suggest a correlative approach for SOFC experiments in the laboratory, where the pore phase distribution may be studied multiple times using laboratory nano-CT, potentially after the specimen has been exposed to different environmental conditions; as a final pass, FIB-SEM may be used to reliably segment the Ni and YSZ phases. The agreement between the porosity data obtained using nano-CT in high resolution and large FOV modes suggest that, for this sample, a sacrifice in maximum resolution can be coupled to an increase in sample volume without compromising key microstructural data. Whilst the requirements for resolution and volume characterized are certainly sample dependent, the variable FOV technique described here may prove valuable in optimizing this balance.

References

[1] N.P. Brandon and D.J. Brett, Philosophical Transactions of the Royal Society a-Mathematical Physical and Engineering Sciences, 364 (2006) 147. 
[2] P.R. Shearing, J. Gelb, N.P. Brandon, J. Eur. Cer. Soc, in press.

[3] J. Banhart, Advanced Tomographic Methods in Materials Research and Engineering, Oxford University Press, Oxford, 2008.

[4] A. Tkachuk et. al., Z. Kristallogr., 222 (2007) 650-655.

[5] Shearing, P.R., et al., 3D reconstruction of SOFC anodes using a focused ion beam lift-out technique. Chemical Engineering Science, 2009. 64(17): p. 3928-3933.

[6] This work has been supported by the EPSRC Supergen fuel cells programme. The authors wish to acknowledge EPSRC grant GR/T26344 for access to image processing software

TABLE 1. The results of the correlative study are presented here, grouped by instrument, showing the calculated volume percentage of each phase as well as the percolated TPB density.

\begin{tabular}{|c|c|c|c|c|c|c|c|c|c|c|}
\hline \multirow[t]{2}{*}{$\begin{array}{l}\text { Imaging } \\
\text { Instrument }\end{array}$} & \multicolumn{3}{|c|}{$\begin{array}{c}\text { Voxel } \\
\text { Dimensions } \\
(\mathrm{nm})\end{array}$} & \multicolumn{3}{|c|}{$\begin{array}{l}\text { Reconstruction } \\
\text { Volume } \\
(\mu \mathrm{m})\end{array}$} & \multicolumn{3}{|c|}{ Volume \% } & \multirow[t]{2}{*}{$\begin{array}{l}\text { Percolated TPB } \\
\text { Density }\left(\mu \mathrm{m}^{-2}\right)\end{array}$} \\
\hline & $X$ & $\mathrm{Y}$ & $\mathrm{Z}$ & $\mathrm{X}$ & $\mathrm{Y}$ & Z & $\mathrm{Ni}$ & YSZ & Pore & \\
\hline $\begin{array}{c}\text { nanoXCT } \\
\text { (highest } \\
\text { resolution) }\end{array}$ & 32 & 32 & 32 & 11.78 & 6.27 & 4.48 & \multicolumn{2}{|c|}{91.19} & 8.81 & - \\
\hline $\begin{array}{c}\text { nanoXC } T^{\mathrm{TM}} \\
\text { (largest field of } \\
\text { view) }\end{array}$ & 65 & 65 & 65 & \multicolumn{3}{|c|}{$37945\left(\mu \mathrm{m}^{3}\right)$} & \multicolumn{2}{|c|}{90.75} & 9.25 & - \\
\hline Cross-beam ${ }^{\mathrm{TM}}$ & 20 & 20 & 19 & 17.80 & 12.18 & 3.33 & 63.17 & 27.41 & 9.42 & 4.25 \\
\hline
\end{tabular}
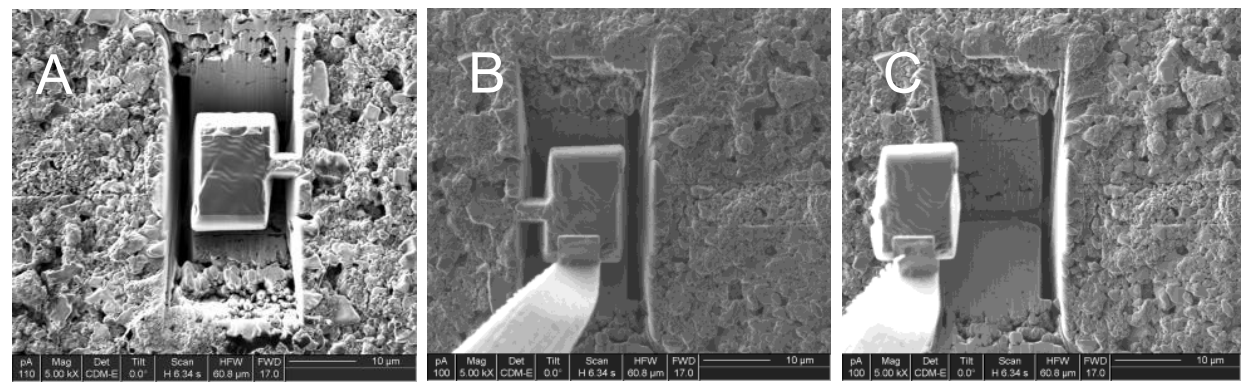

FIG. 1. The sample was prepared by using a FIB to first mill out an optimal geometry for nano-CT, leaving a small connecting bridge in place (A). The milled region was then welded to a tungsten needle using a Pt gas-injection system (B) and then the bridge detached by ion-beam milling (C).
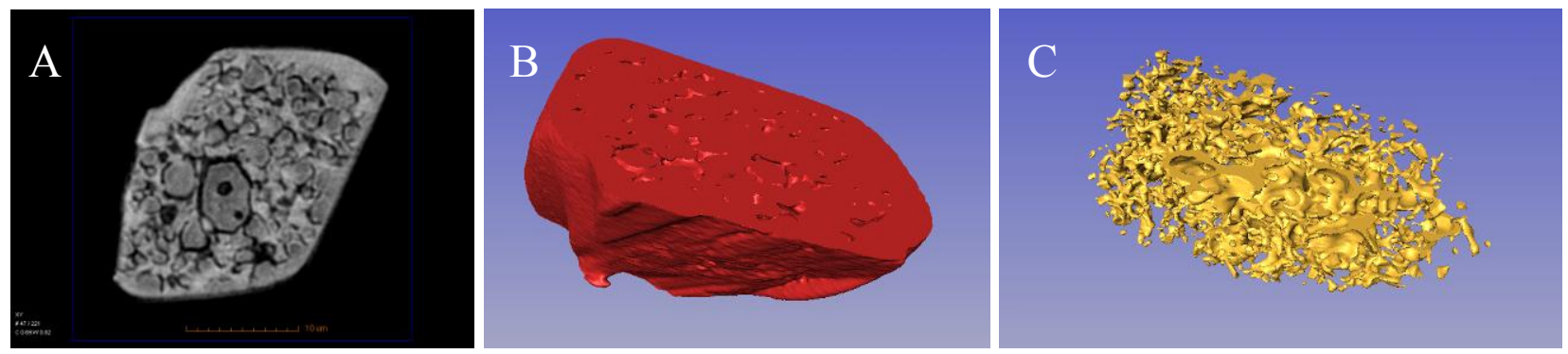

FIG. 2. The $\mathrm{x}$-ray nanotomography data is shown here, utilizing $150 \mathrm{~nm}$ resolution. Shown is a single virtual slice (A), the solid-phase segmentation (B), and the pore-phase segmentation (C). 